\title{
Study on Synthesis Of Oxetan-3-ol
}

\section{Tianxiang $\mathrm{Xu}^{1, \mathrm{a}}$, Xiao Leng ${ }^{1, \mathrm{~b}}$, Shuangping Huang ${ }^{1, \mathrm{c} *}$ and Xiaoji Wang ${ }^{1, \mathrm{~d} *}$}

${ }^{1}$ School of Pharmacy, Jiangxi Science and Technology Normal University, Jiangxi, 330013, China.

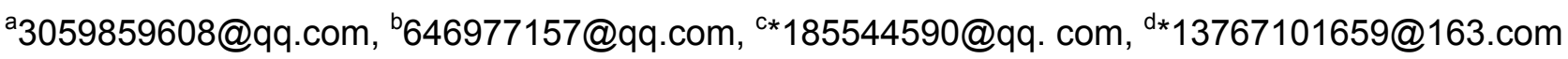

Keywords: 3-oxetanone, synthesis, ring-closure reaction.

Abstract. One concise methods for synthesis of oxetan-3-ol from epoxy chloropropane are reported. The method involve employsepoxy chloropropane opening of reaction, esterifiction, electrophilic reaction, ring-closure reaction.

\section{Introduction}

Oxetan-3-ol (Fig.1) is a epoxybutane homologue, possessing a important impact on structural modification. As an important building block, an oxetane can trigger profound changes in aqueous solubility, lipophilicity, metabolic stability, and conformational preference when replacing commonly employed functionalities such as gem-dimethyl or carbonyl groups [1,2]. Therefore, as the important source of oxetane unit, oxetan-3-ol plays an important role in the drug development.

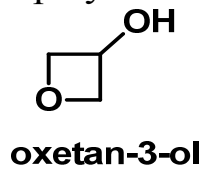

Fig. 1 Structure of oxetan-3-ol and the related molecule.

Oxetan-3-ol is usually used for the preparation of 3-oxetanone. and the compounds containing such oxetanone moiety have been often used in synthetic and medicinal chemistry. Recently, Carreira and coworkers explored to use the oxetanone unit as a gem-dimethyl variant to modify solubility, lipophilicity, metabolic stability, and molecular conformation [3]. Oxetan-3-ones are also useful in synthesis and drug discovery and can serve as precursors to oxetanones, as well as oxetan-3-one, 1,3-epoxy-2-propanone, and other oxetane derivatives are also useful in serving as precursors to oxetanones [4]. Chemerda et. al also reported that steroids involving oxetan-3-ones possessed novel bioactivity, such as antiinflammatory and antiglucocorticoid [5]. Owing to the considerable diversity of possible oxetanthe synthetic approaches to oxetan-3-ol was urgent to develop, and actually there are a limited number of routes described. Recently, Zhang reported gold catalyzed oxidative cyclization of propargyl alcohol [6]. Ryono et. al developed a four steps route to construct oxetan-3-ol [7]. We believed an efficient and concise route to synthesize this useful oxetane is necessary. So based on A's report, we developed a modified approach to obtain oxetan-3-ol.

Our retrosynthesis was depicted in Figure 2. The target oxetan-3-ol was disconnected to protected (2). The intermediate (2) was devised to obtain from chloride (3) via two steps via a hydrolysis and an intramolecular cyclization. For synthesis of (3), it would be disconnected to alcohol (4) through a protection. The later was designed to be got from commercially available epoxy chloropropane (5).

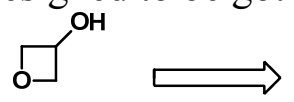

(1)

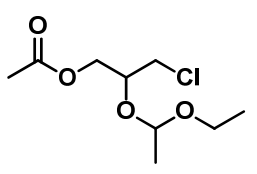

(3)

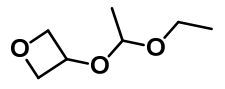

(2)

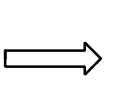

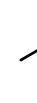

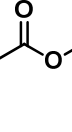

(4)

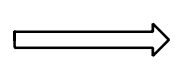

(1)

Fig. 2 Retrosynthetic route of oxetan-3-ol 
Our synthetic route was shown in scheme 1. Our route commenced with commercially available epoxy chloropropane (5). In the presence of catalytic anhydrous Iron (Ш) chloride (without further drying), epoxy chloropropane reacted with acetic acid at $70^{\circ} \mathrm{C}$ to give (4) in $90 \%$ yield. Chloride (4) proceeded smoothly a protection on treatment with ethyl vinyl ether under the condition of weak acid p-TsOH at $35{ }^{\circ} \mathrm{C}$ to afford (3). We initially isolated the intermediate (3) on silical gel and take the pure (3) into the next hydrolysis and cyclization, however, only little (3) were obtained. Considering the instability of hemiacetal, we straight used the crude protection product (3) in the next without purification. Therefore, after protection using ethyl vinyl ether, the crude immediately treated with aqueous $\mathrm{NaOH}$ at high temperature $\left(110{ }^{\circ} \mathrm{C}\right)$. When the TLC indicated the consumption of starting material, the resulting mixture was cooled down to room temperature and subjected to the subsequent deprotection without further purification. The whole route took four steps involving three steps that proceeded without purification. Finally we finished the synthesis of the desired oxetan-3-ol in overall $38.75 \%$ yield.

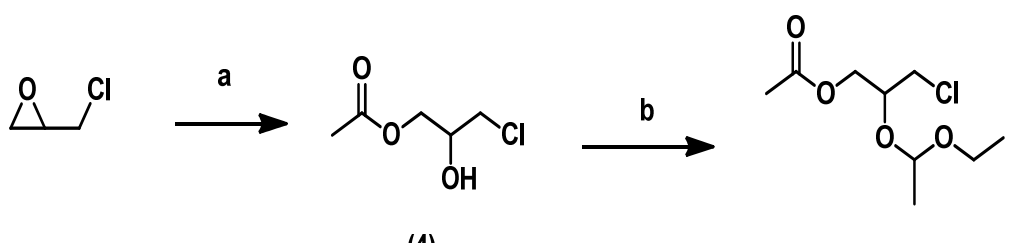

(5)

(4)

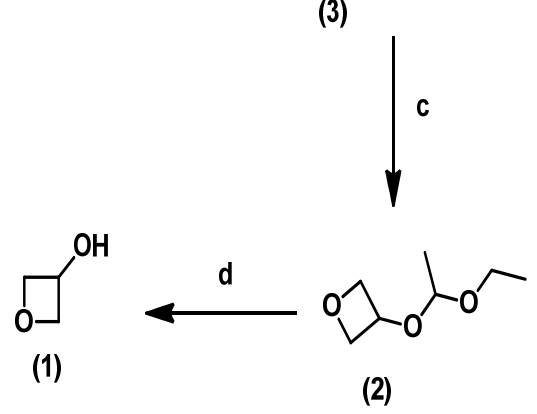

a) HOAc, Iron (Ш) chloride anhydrous, $70^{\circ} \mathrm{C} .12 \mathrm{~h}, 90 \%$;

b) ethyl vinyl ether, $\mathrm{p}-\mathrm{TsOH}, 35^{\circ} \mathrm{C} .8 \mathrm{~h}$;

c) $\mathrm{NaOH}, \mathrm{H}_{2} \mathrm{O}, 110{ }^{\circ} \mathrm{C} .4 \mathrm{~h}$;

d) $\mathrm{MeOH}, \mathrm{p}-\mathrm{TsOH}, 15-18^{\circ} \mathrm{C}$. then $\mathrm{NaHCO}_{3}, 1 \mathrm{~h}, 30 \%$.

Fig. 3 synthesis of oxetan-3-ol

\section{Experimental}

NMP spectra were record on a BRUKER AV-400MHz NMR (Nuclear magnetic Resonance). The chemical shifts are recorded relative to an internal standard of 3-oxetanone.All coupling constants , J, are reported in Hertz. All solvents are refined by standard method.

\section{Acetic acid-2-hydroxy-3-chloropropyl ester (4)}

To a solution of $\mathrm{FeCl}_{3}(0.97 \mathrm{mg}, 0.006 \mathrm{mmol})$ in $\mathrm{HOAc}(1.23 \mathrm{ml}, 21.6 \mathrm{mmol})$ was added 2( chloromethyl ) oxirane $(2 \mathrm{~g}, 21.6 \mathrm{mmol})$ with stirring, over a 5 -min period. The mixture was heated at $70^{\circ} \mathrm{C}$.with stirring for $12 \mathrm{~h}$, then was cooled to $\mathrm{rt}$ and extracted with DCM, The solution was concentrated in vacuo To give Acetic acid-2-hydroxy-3-chloropropyl ester $(2.97 \mathrm{~g}, 90 \%$ yield) as a yellow oil. ${ }^{1} \mathrm{H}$ NMR $\left(400 \mathrm{MHz}, \mathrm{CDCl}_{3}\right)(2.15(\mathrm{~s}, 3 \mathrm{H}), 3.65-3.95(\mathrm{~m}, 2 \mathrm{H}), 4.10-4.15(\mathrm{~m}, 1 \mathrm{H}), 4.35(\mathrm{t}$, $\mathrm{J}=4.89 \mathrm{~Hz}, 2 \mathrm{H})$.

\section{Acetic acid 2(1-ethoxy ) ethoxy-3-chloropropyl ester (3)}

To crude part Acetic acid-2-hydroxy-3-chloropropyl ester compound (1.5 g $9.8 \mathrm{mmol})$ was added para-toulenesulfonic acid(p-TsOH) $(6.7 \mathrm{mg}, 0.039 \mathrm{mmol})$, followed by dropwise addition of ethyl vinyl ether $(0.95 \mathrm{ml}, 10.03 \mathrm{mmol})$ at $\mathrm{rt}$ over a period of $0.3 \mathrm{~h}$. The flask was cooled to maintain a reaction temperature of 30-35. After the addition was complete, the mixture was heated at 40-45 ${ }^{\circ} \mathrm{C}$.for $8 \mathrm{~h}$, then cooled to $\mathrm{rt}$. The mixture was extracted with DCM, the combined organic 
extracts was concentrated in vacuo to give crude Acetic acid 2 (1-ethoxy) ethoxy-3-chloropropyl ester compound $(1.9874 \mathrm{~g})$ as a red liquid.

\section{3- (ethyloxy) oxetane (2)}

To a $110^{\circ} \mathrm{C}$. solution of $\mathrm{NaOH}(407.26 \mathrm{mg}, 10.1816 \mathrm{mmol})$ in water $(0.4 \mathrm{ml})$ was added crude Acetic acid 2 (1-ethoxy) ethoxy-3-chloropropyl ester compound ( $1 \mathrm{~g}, 4.45 \mathrm{mmol})$ over a $1.5 \mathrm{~h}$ period. The reaction mixture was refluxed for another $4 \mathrm{~h}$. Then was cooled to $\mathrm{rt}$ and wash with water $(10 \mathrm{ml})$, the aqueous layer was extracted with DCM $(100 \mathrm{ml})$, and the combined organic extracts were concentrated in vacuo to give a brown oil. Distillation $\left(\mathrm{bp}=45-50^{\circ} \mathrm{C} @ 0.5 \mathrm{mmHg}\right.$ ) to give 3-(ethyloxy) oxetane compound (250mg, $30 \%)$ as a clear oil.

oxetane-3-ol (1)

A solution of 3- (ethyloxy) oxetane $(250 \mathrm{mg}, 1.92 \mathrm{mmol})$ in $\mathrm{MeOH}$ ( $2.3 \mathrm{mmol})$ was cooled to $15-18^{\circ} \mathrm{C}$., and p-TsOH was added with stirring. The reaction mixture was stirred for 45 min , when the reaction was finished quenched with $\mathrm{NaHCO}_{3}$. Distillation at $35-40^{\circ} \mathrm{C} .(0.1 \mathrm{mmHg})$ gave crude oxetane-3-ol compound as a clear oil. ${ }^{1} \mathrm{H}$ NMR $\left(400 \mathrm{MHz}, \mathrm{CDCl}_{3}\right) \delta 3.58(\mathrm{~s}, 1 \mathrm{H}), 4.45(\mathrm{t}, 1 \mathrm{H})$, 4.88-5.00 (m, $2 \mathrm{H})$.

\section{Acknowledgement}

We gratefully thank the National Natural Science Foundation of China (No.21562020), Science and Technology Research Projects of the Education Department of Jiangxi Province (No. GJJ14579 ), Science and Technology Plan Project of Jiangxi Province (No. 20142BBE50006), Scientific Rese arch Fund of Jiangxi Provincial Education Department (No. KJLD12036), Training Fund for Excell ent young scientist of JiangXi Province (No. [2013]138) for the funding support.

\section{References}

[1] G. Wuitschik, M. Rogers-Evans, K. Muller, H. Fischer, B. Wagner, F. Schuler, L. Polonchuk, E, M.Carreira, Oxetanes as Promising Modules in Drug Discovery Chem. Int. Ed. 45 (2006) 7736-7739.

[2] G. Wuitschik, M. Rogers-Evans, K. Muller, H. Fischer, B. Wagner, F. Schuler, M.Carreira, Oxetanes in Drug Discovery: Structural and Synthetic Insights, Angew. J. Med. Chem. 53 (2010) 3227-3246.

[4] G. Chemerda, S. Hasegawa, S. Saito, N. Shimada, T.Takita, Synthesis and antiviral activity of oxetanocin derivatives, Teterahedron Lett. 32 (1991) 3531-3534.

[5] Y.Dejaegher, M.N.Kuzomenok, A.M. Zvonok, The Chemistry of Azetidin-3-ones, Oxetan-3-ones, and Thietan-3-ones, Chem. Rev. 102 (2002) 29-60.

[6] P.L. Hamzik,J.D. Brubaker, Reactions of Oxetan-3-tert-butylsulfinimine for the Preparation of Substituted 3-Aminooxetanes, Org. Lett. 12 (2010) 1116-1119.

[7] D.E.Rvono, T.W.Peter,A.B.Scott, U.S. Patent 1,85,514.(2001) 